\title{
Influences of maternal mental illness on psychological outcomes for adolescent children
}

\author{
Daphna Oyserman, Deborah Bybee and Carol Mowbray
}

\begin{abstract}
The research literature associating maternal mental illness with problematic mental health outcomes of adolescent children typically controls for neither the effects of family stresses and lack of support, nor the effects of parenting style. To address this gap, we explore the effects of maternal psychiatric symptoms and community functioning on child outcomes in a diverse sample of seriously mentally ill women caring for their teenaged children. In hierarchical multiple regression, for youth depression, we find effects for parenting style and maternal mental health; for youth anxiety and efficacy, effects involve the interplay between maternal symptoms and community functioning.
\end{abstract}

(C) 2002 The Association for Professionals in Services for Adolescents Published by Elsevier Science Ltd. All rights reserved.

\section{Introduction}

In the current study, we focus on effects of maternal mental illness on an adolescent's psychological well-being. That maternal mental illness is negatively associated with mental health outcomes of children (though not specifically adolescents) is amply evidenced in recent studies (e.g. for maternal depression: Hammen et al. (1987 a,b) for bipolar disorder, Duffy et al. (1998); Grigoroiu-Serbanescu et al. (1991); for schizophrenia, Arbelle et al. (1997) and reviews (e.g. Beardslee et al., 1998). These studies typically find that maternal mental illness is associated with child mental health problems (for a review focused on maternal depression see Downey and Coyne (1990); for a meta-analysis focused on bipolar disorder see Lapalme et al. (1997). Moreover, the literature on biological transmission of disorders indicates genetic vulnerability for children of parents with a serious mental illness, with strength of genetic vulnerability varying - being lower for depression and higher for bipolar disorder and schizophrenia (Beardslee et al., 1998).

However, outcomes for children of parents with even severe mental illness are heterogeneous, and ways that parental psychopathology may influence outcomes for their children is far from clear (see Beardslee et al. (1998) for a review). Unfortunately, most recent research on children of parents with severe mental illness has studied the relationship between parental diagnosis and child diagnosis without taking family stresses, contextual issues (see for example Chang et al., 2000) or parenting into account (for a review, see Oyserman et al., 2000), especially in research on adolescents.

Thus, even though the literature has clearly documented increased risk for children of mothers with a mental illness, more research is needed to understand the process by which risk is conferred. First, as noted in meta-analyses of effects of having a bipolar parent (Laplame et al., 1997), research lacks sufficient focus on the adverse social and contextual factors associated with maternal mental illness and has not disentangled the effects of maternal symptoms and functioning from the effects of problematic parenting and other

Reprint requests and correspondence should be addressed to: Dr Daphna Oyserman, Institute for Social Research, University of Michigan, 426 Thompson, Ann Arbor, MI 48109-1248, U.S.A. (E-mail: daphna@umich.edu). 
family stresses on children's outcomes. Second, research tends to focus on two-parent families, reducing the range of parent stresses that could influence children's outcomes. These gaps are important because the existing literature suggests that poverty, marital disruption, single parenting and social isolation are more common among mothers with mental illnesses and that these problems themselves are associated with negative outcomes for children (Oyserman et al., 2000).

Moreover, when family relationship issues are studied, researchers often focus either on marital adjustment, marital discord or on the quality of parenting, and do not consider simultaneously parenting and other family stresses (for an exception see, Fendrich et al., 1990). Further, much research has focused specifically on mothers with depression, though when studied, the family and context factors associated with parental bipolar disorders seem quite similar to those associated with depression (Laplame et al., 1997), suggesting that a broader perspective on mental illness might be warranted.

Researchers who do study family and context variables find that they are critical towards understanding psychological well-being of adolescents. For example, in an Australian sample, Fergusson, et al. (1995) found that the association between maternal depressive symptoms (coded both as mean symptoms and as number of years till the child's 13th birthday that a mother experienced these symptoms) and adolescent depressive symptoms was no longer significant once social and contextual risk factors were added to the analyses. Similarly, using a probability sample of Ontario, Canadian residents with children aged 4-16, Boyle and Pickles (1997) examined the relationship between maternal and child depressed mood (using the Child Behaviour Checklist), co-varying on family dysfunction and economic hardship. They also found a significantly reduced association between maternal and child symptoms when they accounted for the influence of contextual factors - the association between mother and child symptoms was lower and remained significant only for girls. Davies and Windle (1997) also found that family factors mediate the relationship between maternal and adolescent depressive symptoms, especially for girls.

These and other authors argue that maternal depressive symptoms are disruptive of the parent-child bond, which in turn increases the risk of problematic child outcomes (Conger, et al., 1995) and that other caretakers can buffer children from the negative effects of depressive symptoms in the parent with mental illness (Tannenbaum and Forehand, 1994). A parallel but distinct argument is that the presence of family disruption (e.g. divorce) potentiates the negative effects of depression (Beardslee, et al., 1993). Thus, research that has included a focus on family context underscores its importance in predicting youth outcomes.

\section{Current Study}

In the current study, we add to the emerging body of research studying contextual influences on outcomes for mothers with a mental illness by utilizing a more diverse sample of mothers in terms of their diagnosis, their living arrangements and their racial-ethnic backgrounds and by using a broader range of measurements of both maternal psychiatric status and maternal supports and stresses than the previously cited studies.

Specifically, we examine mothers who meet DSM-IV criteria for serious mental illness-major depression, bipolar disorder and schizophrenia, include in our sample mothers with diverse living arrangements (single parents, mothers living with relatives, 
mothers living with a spouse or partner) and mothers and youth from a variety of racialethnic groups. Further, we use multiple measures of family stress and parenting, including maternal support, hassles, family poverty and permissive as well as authoritative parenting. Rather than limit our analyses to two-parent white families, as did much of the previous research, we include a more ecologically valid heterogeneous and racially diverse sample of women with a serious mental illness who are providing care for their teenaged children.

Following the literature, we hypothesize that family stresses and parenting style will significantly predict a teen's psychological well-being, and that they will play at least as important a role as maternal diagnosis, symptoms of mental illness and functioning.

\section{Method}

\section{Participants}

The participants were 70 mother-youth dyads, part of a larger study of mothers with a serious mental illness. Mothers were living in the community and had not been hospitalized in the month prior to interview so that maternal functioning was stable at the time of interview. A full description of the mothers is available elsewhere (Mowbray et al., 2000). In the subsample studied here, 33\% of mothers described themselves as African American, 60\% described themselves as Caucasian, 3\% described themselves as Hispanic, and $4 \%$ as American Indian or Alaskan Native. For youths, 24\% described themselves as African American, $50 \%$ as Caucasian, $1 \%$ as Hispanic, and 24\% as biracial or "other". Mothers were 39 years of age on average (S.D. $=5 \cdot 65$, range: $29 \cdot 9-57 \cdot 3$ years), and youth were, on average, $13 \cdot 1$ (s.D. $=1 \cdot 46) ; 34$ were male, 36 female. Youth chosen for the interview were the mother's youngest child in the age range 11-17 years of age. At the time of the mother's interview, $30.4 \%$ of mothers were married, $10 \cdot 1 \%$ separated, $33 \cdot 3 \%$ divorced, $4 \cdot 3 \%$ widowed, and $21.7 \%$ were single. Of those not currently married, $17 \%$ were living with a partner, so that over half of the sample was neither married nor living with a partner.

\section{Sampling procedure}

Mothers living in two counties in southeast Michigan (including the City of Detroit), who had to the responsibility care for one or more of their children and were receiving Community Mental Health services for a serious mental illness that had lasted at least a year, were asked to participate. Youth interviews were conducted on an average of two years $(M=$ $95 \cdot 3$ weeks, S.D. $=26 \cdot 79$ weeks) after maternal interviews. After obtaining maternal permission, we contacted the youths and asked them to participate in a study of adolescent transitions. We emphasized that participation was voluntary and confidential, and we assured mothers that we would not share any information about her situation with the youth. Written informed consent (guardian) and assent (youth) were obtained before the interview. Mothers and youth were reimbursed for participating. Interviews of approximately $2 \mathrm{~h}$ length took place in the privacy of participants' homes. Interviewers were provided a snack and a break midway through the interview. Interviewers were women, aged 20-45; all had prior experience with children, were currently university students, or had undergraduate degrees. They received an extensive 3 -day training in interview administration.

For mothers, $78 \%$ of those eligible completed all of the data collection in the larger study (full description is available in Mowbray et al., 2000). To obtain a youth sample for this study, we used the following procedure: first, we identified potentially eligible youth from maternal 
interviews, with a goal of obtaining a sample of 70 adolescents roughly balanced by age and gender. Next, we contacted mothers to request consent to contact the youth, clarifying that the youth was cognitively able to understand an interview and was available (e.g. not currently living away from home). Then we made three attempts to contact each youth, with the process continuing until 70 youths were interviewed. In total, 76 guardians and youth agreed for the youth to be interviewed; 30 refused (the remaining six youths were not interviewed due to budget constraints), for an agreement rate of $71 \cdot 7 \%$.

\section{Measures}

Measures obtained from the maternal interview Adjusted family income. We obtained the total monthly household income $(M=\$ 1311 \cdot 97$; S.D. $=715 \cdot 42, \mathrm{Mdn}=$ $1195 \cdot 00$, range $=0-3900 \cdot 00$ ) using a checklist of potential sources; adjusted income was created as a per cent of the federal poverty line (U.S. Census Bureau, 1996), adjusted for household size $(\mathrm{M}=101 \cdot 72 \%$, S.D. $=54 \cdot 0 \%, \mathrm{Mdn}=88 \cdot 7 \%)$.

Stress and social support Although the literature cited in the introduction focused on measures of marital support and conflict, given the nature of our sample, with most mothers not married or living with a partner, we assessed the mother's daily stress and parenting supports more broadly. We measured daily hassles using an 18-item version of the Hassles and Uplifts Scale (Lazarus and Folkman, 1984), including hassles due to work, health, family, friends, environment and daily chores $(M=9 \cdot 69$, S.D. $=3 \cdot 41$, range $=1-16)$. We scored parenting social support by counting the number of people available to the mother for parenting advice or childcare in the past month $(\mathrm{M}=3 \cdot 91$, S.D. $=2.12$, range $=0-11)$, following a version of the Arizona Social Support Interview Schedule (Barrera, 1988). To reduce skew, we used the natural log of this variable for analysis.

Maternal parenting style. We coded maternal parenting style from responses to four scenarios adapted from the Sensitivity to a Children Scale (Stollak et al., 1973), using an operationalization of Baumrind's (1978) description of parenting style. Each scenario described a problematic child behaviour of a 4-year old, such as not wanting to go to bed or having a temper tantrum in a public place. Mothers described what they would do or say when this happened. Two project staff coded responses for positive directive or permissive parenting, summing across all four scenarios: positive directives $(M=0 \cdot 74$, S.D. $=0 \cdot 89$, range $=0-3, \kappa=0.74)$; permissive parenting $(M=0.42$, S.D. $=0.63$, range $=0-3, \kappa=0.75)$.

Maternal mental health symptoms and functioning. We assessed maternal diagnosis with the DIS, a structured interview protocol for use with lay interviewers. Approximately, half the women met DSM-IV diagnostic criteria for major depressive disorder (34 or 48.6\%); $19(27 \cdot 1 \%)$ women criteria for bipolar disorder; $14(20 \cdot 0 \%)$ women met the criteria for a diagnosis of schizophrenia or schizoaffective disorder; for three women $(4 \cdot 3 \%)$, DIS interview information was not sufficient to determine diagnosis. Maternal symptoms (depressive and psychotic) were measured with the Colorado Symptom Index (Shern et al., 1994), a 14-item, five-point symptom frequency scale $(1=$ never, $2=$ once a month or less, $3=$ several times a month, $4=$ several times a week, $5=$ at least every day $)(M=2 \cdot 80$, S.D. $=0 \cdot 77$, range $=$ 1.29 to $4 \cdot 46 ; \alpha=0 \cdot 89)$. Community functioning in the month prior to the maternal interview was measured with an 18-item, five-point Likert self-report scale $(1=$ very difficult/hardly ever to $5=$ not at all difficult/frequently). Items included doing daily chores, handling finances and crises, engaging in social activity and managing conflict, and utilizing 
treatment resources $(M=3 \cdot 38$, S.D. $=0.51$, range $=2 \cdot 47-3.42 ; \alpha=0 \cdot 78$; Bybee et al., 2001).

Measures obtained from the child's interview Depression. We assessed youth depressive symptoms with the Children's Depression Inventory (Cole et al., 2000; Kovacs, 1992), a widely used 27-item scale to assess depressive symptoms. Youth were asked to endorse on one of three alternative responses for each item where response $0=$ absence of symptom, 1 = mild symptom, and 2 = definite symptom. For example, item one reads "I am sad once in a while" (0), "I am sad many times" (1), "I am sad all the time" (2). The sum of responses, ranging from 0 to 54 , is the depressive symptom score $(M=8 \cdot 92$, S.D. $=7 \cdot 24$, actual range $=0-40, \alpha=0 \cdot 88)$. Five youth $(7 \cdot 1 \%)$ met clinical depression criteria (cut point of 20).

Anxiety. We assessed youth symptoms of anxiety with the Revised Children's Manifest Anxiety Scale (Reynolds, 1985; Cole, et.al. 2000). This widely used scale consists of 39 dichotomous response items (yes/no). For example "I have trouble making up my mind," "I worry a lot of the time", and "I get mad easily". Following Reynolds (1985), we obtained normalized T-scores $(M=48 \cdot 89$, S.D. $=11 \cdot 56$, sample range: $31-87, \alpha=0 \cdot 89)$, dropping the 9 social desirability items.

School efficacy. Perceived academic self-efficacy was assessed using a six-item $(1=$ almost never, to 5 = almost always) sub-scale from the Bandura Self-efficacy measure (Bandura et al., 1996). Sample items are "How well can you live up to what your teachers expect of you?" and "How well can you participate in class discussions?" ( $M=3 \cdot 90$, s.D. $=0 \cdot 73$, range $=1 \cdot 3-6, \alpha=0 \cdot 71)$.

\section{Results}

\section{Analysis plan}

Preliminary analysis examined child depression, anxiety, and school efficacy by maternal diagnosis, using multivariate analysis of variance. As can be seen in Table 1, none of the child outcomes differed by maternal diagnosis. Diagnosis also was not related to any of the

Table 1. Multivariate analysis of variance on child outcomes by maternal diagnosis

\begin{tabular}{|c|c|c|c|c|c|}
\hline \multirow[b]{2}{*}{ Child outcomes } & \multicolumn{3}{|c|}{ Mean (S.D.) within diagnostic group } & \multicolumn{2}{|c|}{ Univariate $F$} \\
\hline & $\begin{array}{l}\text { Major depression } \\
(n=34)\end{array}$ & $\begin{array}{l}\text { Bipolar disorder } \\
\quad(n=19)\end{array}$ & $\begin{array}{l}\text { Schizophrenia } \\
\quad(n=14)\end{array}$ & $F_{(2,64)}$ & $p$ \\
\hline Child depression & $\begin{array}{l}9 \cdot 00 \\
(8 \cdot 44)\end{array}$ & $\begin{array}{l}9 \cdot 00 \\
(5 \cdot 76)\end{array}$ & $\begin{array}{c}9 \cdot 14 \\
(6 \cdot 95)\end{array}$ & 0.00 & 0.99 \\
\hline Child anxiety & $\begin{array}{r}8 \cdot 76 \\
(6 \cdot 75)\end{array}$ & $\begin{array}{l}10 \cdot 63 \\
(6 \cdot 42)\end{array}$ & $\begin{array}{l}11 \cdot 64 \\
(8 \cdot 64)\end{array}$ & 0.96 & $0 \cdot 39$ \\
\hline Child school efficacy & $\begin{array}{l}3 \cdot 94 \\
(0 \cdot 85)\end{array}$ & $\begin{array}{l}3 \cdot 75 \\
(0 \cdot 58)\end{array}$ & $\begin{array}{l}3 \cdot 98 \\
(0 \cdot 70)\end{array}$ & $0 \cdot 47$ & 0.63 \\
\hline Multivariate $F_{(3,62)}=$ & $90, p=0.50$ & & & & \\
\hline
\end{tabular}

Note: Group variances were not significantly different for any of the three dependent variables, according to Levene's test for homogeneity of variances. 
demographic variables (mothers' race, age, marital status, living situation, household income) or to stress, social support, parenting style, or maternal symptoms or functioning in the previous month. Because diagnosis did not relate to any of the variables of interest, we focused further analyses on maternal symptoms and functioning as follows.

We used hierarchical regression to study the possible effects of maternal mental health symptoms and functioning once child demographic variables (child age, gender, and race; block 1), family stress (income level, hassles, lack of support for parenting; block 2), and maternal parenting style (block 3) had been taken into account. Maternal symptoms and functioning were entered in block 4. After graphical inspection of joint effects, a final block 5 was added to reflect the additional explanatory contribution of the interaction of maternal symptoms and functioning. As a final step, the unique effect of each independent variable was examined by sequentially entering each into the equation last, after controlling for all other effects in the model; shared effects were calculated as the difference between the total effect (zero-order $r^{2}$ ) and the unique effect. Power was minimally adequate for these analyses, reaching 0.80 to detect the significance of an individual predictor (at $p<0.05$ ) only when it accounted for a non-redundant $8 \%$ of the variance in youth outcome, assuming the remaining predictors accounted for at least $25 \%$.

Following recommendations of Aiken and West (1991), variables involved in the interaction were centered to facilitate interpretation and reduce the effects of multicollinearity, and effects were interpreted via plots and calculation of simple slopes from unstandardized regression coefficients. Because maternal symptomatology and functioning were significantly correlated $(r=-0.64)$, quadratic effects for both symptomatology and functioning were tested to ensure that the interaction between these variables was not a proxy for a curvilinear effect of either variable alone (Ganzach, 1997). Neither of the quadratic effects was significant, and so they were omitted from the final equations that are presented here.

We report three hierarchical regression analyses, predicting three child outcomes - symptoms of depression, anxiety and school self-efficacy. Although significantly, intercorrelated, as portrayed in Table 2, anxiety, depression, and low feelings of competence in an important life domain such as school are likely to have different consequences. Therefore, we analysed them separately to allow comparison of predictive relationships across different dependent variables and to provide specific outcome information relevant to differing audiences. Tables 3-5 summarize regression results.

\section{Depression}

The hierarchical regression predicting child depression is depicted in Table 3. None of the child demographics or family stress variables related significantly to youth depression (blocks 1 and 2). Youth depression was significantly related to parenting style $(\Delta F(2,60)=5 \cdot 87$, $p<0 \cdot 01 ; \Delta R^{2}=0 \cdot 16$, block 3), which made a significant unique effect. Specifically, higher maternal permissive parenting was associated with higher youth depressive symptoms (unstandardized $B=3 \cdot 96, p<0 \cdot 01$; unique effect $=0 \cdot 10, p<0 \cdot 01$ ), and at trend level, higher maternal report of positive directive parenting was associated with lower youth depressive symptoms $(B=-1 \cdot 70, p<0 \cdot 10$; unique effect $=0 \cdot 03, p<0 \cdot 10)$.

Effects of maternal mental health. Maternal mental health added significantly to variance explained. At block 5 , maternal mental health added significantly to the prediction of youth depressive symptoms, $\left(\Delta F(2,58)=5 \cdot 20, p<0 \cdot 01 ; \Delta R^{2}=0 \cdot 12\right)$; surprisingly, higher 
Table 2. Intercorrelations among child and maternal variables used in regression analyses

\begin{tabular}{|c|c|c|c|c|c|c|c|c|c|c|c|c|c|}
\hline & \multicolumn{6}{|c|}{ Child variables } & \multicolumn{7}{|c|}{ Maternal variables } \\
\hline & Dep. & Anx. & Efficacy & Sex & Race & Age & Income & Hassles & $\begin{array}{l}\text { Sup- } \\
\text { port }\end{array}$ & Perm. & Pos. Dir. & Symp. & Func. \\
\hline \multicolumn{14}{|l|}{ Child variables } \\
\hline Anxiety & $0 \cdot 74$ & & & & & & & & & & & & \\
\hline School efficacy & -0.55 & $-0 \cdot 45$ & & & & & & & & & & & \\
\hline $\operatorname{Sex}(1=M ; 0=F)$ & -0.07 & $-0 \cdot 25$ & -0.06 & & & & & & & & & & \\
\hline Race $(1=W ; 0=N W)$ & 0.03 & $-0 \cdot 13$ & $-0 \cdot 29$ & $0 \cdot 14$ & & & & & & & & & \\
\hline Age & -0.03 & $-0 \cdot 11$ & 0.01 & $0 \cdot 24$ & 0.01 & & & & & & & & \\
\hline \multicolumn{14}{|l|}{ Maternal variables } \\
\hline Income (\% poverty) & $-0 \cdot 14$ & $-0 \cdot 14$ & 0.04 & 0.05 & $0 \cdot 15$ & 0.04 & & & & & & & \\
\hline Daily hassles & 0.02 & 0.06 & $-0 \cdot 13$ & -0.04 & $0 \cdot 10$ & $0 \cdot 13$ & -0.08 & & & & & & \\
\hline Parenting support & 0.08 & 0.04 & $-0 \cdot 20$ & -0.06 & $0 \cdot 11$ & $-0 \cdot 13$ & $0 \cdot 13$ & 0.04 & & & & & \\
\hline Permissive parenting & $0 \cdot 36$ & $0 \cdot 25$ & -0.09 & $-0 \cdot 13$ & 0.04 & -0.02 & -0.07 & $-0 \cdot 12$ & -0.03 & & & & \\
\hline Positive directive parenting & -0.23 & $-0 \cdot 15$ & $0 \cdot 17$ & 0.07 & $-0 \cdot 11$ & $0 \cdot 11$ & -0.02 & $0 \cdot 16$ & $-0 \cdot 18$ & -0.09 & & & \\
\hline Symptoms & $-0 \cdot 26$ & $-0 \cdot 17$ & 0.06 & -0.02 & 0.05 & $0 \cdot 17$ & 0.06 & $0 \cdot 32$ & $-0 \cdot 13$ & $0 \cdot 11$ & $0 \cdot 10$ & & \\
\hline Functioning & -0.07 & $-0 \cdot 17$ & $0 \cdot 10$ & $0 \cdot 16$ & -0.00 & $-0 \cdot 20$ & $0 \cdot 18$ & $-0 \cdot 40$ & 0.22 & $-0 \cdot 26$ & -0.06 & $-0 \cdot 64$ & \\
\hline Symptoms $\times$ functioning & $0 \cdot 32$ & $0 \cdot 32$ & $-0 \cdot 29$ & 0.01 & -0.05 & -0.08 & $-0 \cdot 11$ & $0 \cdot 15$ & 0.04 & -0.03 & 0.04 & $-0 \cdot 21$ & $0 \cdot 10$ \\
\hline
\end{tabular}

Note: Bolded correlations are those that are significantly different from zero at $p<0.05$. 
Table 3. Hierarchical regression predicting child depression

\begin{tabular}{|c|c|c|c|c|c|c|c|}
\hline \multirow[b]{3}{*}{ Blocks of predictors } & \multicolumn{7}{|c|}{ Coefficients } \\
\hline & \multicolumn{2}{|c|}{ Entry block } & \multicolumn{2}{|c|}{ Final block } & \multirow[b]{2}{*}{ Block $\Delta R^{2}$} & \multicolumn{2}{|c|}{ Effects } \\
\hline & Unstand. B & S.E. & Unstand. B & S.E. & & Shared & Unique \\
\hline $\begin{array}{l}\text { Block } 1 \text { - Child demographics } \\
\text { Sex }(1=\text { male; } 0=\text { female) } \\
\text { Race }(1=\text { white; } 0=\text { nonwhite }) \\
\text { Age (in years) }\end{array}$ & $\begin{array}{r}-1.06 \\
0.67 \\
-0.08\end{array}$ & $\begin{array}{l}1 \cdot 86 \\
1 \cdot 84 \\
0.63\end{array}$ & $\begin{array}{l}0 \cdot 18 \\
0 \cdot 34 \\
0 \cdot 15\end{array}$ & $\begin{array}{l}1 \cdot 63 \\
1 \cdot 60 \\
0.56\end{array}$ & 0.07 & $\begin{array}{l}0.01 \\
0.00 \\
0.00\end{array}$ & $\begin{array}{l}0.00 \\
0.00 \\
0.00\end{array}$ \\
\hline $\begin{array}{l}\text { Block 2-Family stress } \\
\text { Income (\% poverty) } \\
\text { Daily hassles } \\
\text { Available support for parenting }\end{array}$ & $\begin{array}{r}-2 \cdot 01 \\
0.00 \\
1 \cdot 34\end{array}$ & $\begin{array}{l}1 \cdot 72 \\
0.27 \\
2 \cdot 00\end{array}$ & $\begin{array}{r}-0.42 \\
0.16 \\
0.79\end{array}$ & $\begin{array}{l}1.53 \\
0.27 \\
1.75\end{array}$ & 0.03 & $\begin{array}{l}0.02 \\
0.00 \\
0.00\end{array}$ & $\begin{array}{l}0.00 \\
0.00 \\
0.00\end{array}$ \\
\hline $\begin{array}{l}\text { Block 3-Maternal parenting style } \\
\text { Permissive } \\
\text { Positive directive }\end{array}$ & $\begin{array}{r}3 \cdot 96 \\
-1 \cdot 70\end{array}$ & $\begin{array}{l}1 \cdot 38^{* * *} \\
1 \cdot 00^{*}\end{array}$ & $\begin{array}{r}3 \cdot 93 \\
-1 \cdot 58\end{array}$ & $\begin{array}{l}1.32 * * * \\
0.09 *\end{array}$ & $0 \cdot 16 * * *$ & $\begin{array}{l}0.03 \\
0.02\end{array}$ & $\begin{array}{l}0 \cdot 10 * * * \\
0 \cdot 03 *\end{array}$ \\
\hline $\begin{array}{l}\text { Block 4-Maternal mental health } \\
\text { Symptomatology } \\
\text { Functioning (self-rated) }\end{array}$ & $\begin{array}{l}-4 \cdot 38 \\
-3 \cdot 08\end{array}$ & $\begin{array}{l}1 \cdot 38^{* * *} \\
2 \cdot 39\end{array}$ & $\begin{array}{l}-3 \cdot 71 \\
-3 \cdot 40\end{array}$ & $\begin{array}{l}1 \cdot 36^{* * *} \\
2 \cdot 30\end{array}$ & $0 \cdot 12 * * *$ & $\begin{array}{l}-0.01 \\
-0.02\end{array}$ & $\begin{array}{l}0.08 * * * \\
0.02\end{array}$ \\
\hline $\begin{array}{l}\text { Block } 5 \text {-Interaction } \\
\text { Functioning } \times \text { symptoms }\end{array}$ & $4 \cdot 78$ & $1.97 * *$ & $4 \cdot 78$ & $1.97 * *$ & $0.06^{*}$ & 0.04 & $0.06 * *$ \\
\hline Overall $\mathrm{F}_{(11,57)}=3 \cdot 17 * * *$ & & & Total $R^{2}=$ & & $0 \cdot 38 * * *$ & & \\
\hline
\end{tabular}

Note: Unique effects are the change in $R^{2}$ attributable to each predictor with the effects of all other predictors controlled. Shared effects reflect the difference between the zero-order $r^{2}$ for the predictor and the unique effect of that predictor. Negative shared effects reflect reciprocal suppression between symptomatology and functioning. $* p<0 \cdot 10, * * p<0 \cdot 05, * * * p<0 \cdot 01$. 
Table 4. Hierarchical regression predicting child anxiety

\begin{tabular}{|c|c|c|c|c|c|c|c|}
\hline \multirow[b]{3}{*}{ Blocks of predictors } & \multicolumn{7}{|c|}{ Coefficients } \\
\hline & \multicolumn{2}{|c|}{ Entry block } & \multicolumn{2}{|c|}{ Final block } & \multirow[b]{2}{*}{ Block $\Delta R^{2}$} & \multicolumn{2}{|c|}{ Effects } \\
\hline & Unstand. B & S.E. & Unstand. B & S.E. & & Shared & Unique \\
\hline Block 1 - Child demographics & & & & & 0.07 & & \\
\hline Sex $(1=$ male; $0=$ female $)$ & $-2 \cdot 97$ & $1 \cdot 74 *$ & $-1 \cdot 79$ & $1 \cdot 64$ & & 0.05 & 0.01 \\
\hline Race $(1=$ white; $0=$ nonwhite $)$ & $-1 \cdot 31$ & $1 \cdot 72$ & $-1 \cdot 58$ & $1 \cdot 62$ & & $0 \cdot 01$ & 0.01 \\
\hline Age (in years) & $-0 \cdot 28$ & 0.59 & $-0 \cdot 25$ & $0 \cdot 56$ & & $0 \cdot 01$ & $0 \cdot 00$ \\
\hline Block 2-Family stress & & & & & 0.02 & & \\
\hline Income (\% poverty) & $-1 \cdot 27$ & $1 \cdot 62$ & $0 \cdot 29$ & $1 \cdot 55$ & & 0.02 & 0.00 \\
\hline Daily hassles & $0 \cdot 13$ & $0 \cdot 26$ & $0 \cdot 12$ & $0 \cdot 27$ & & $0 \cdot 00$ & 0.00 \\
\hline Available support for parenting & $0 \cdot 70$ & $1 \cdot 88$ & $0 \cdot 68$ & $1 \cdot 77$ & & $0 \cdot 00$ & $0 \cdot 00$ \\
\hline Block 3-Maternal parenting style & & & & & $0.07 *$ & & \\
\hline Permissive & $2 \cdot 60$ & $1 \cdot 36^{*}$ & $2 \cdot 17$ & $1 \cdot 33$ & & 0.03 & 0.03 \\
\hline Positive directive & $-1 \cdot 14$ & $0 \cdot 98$ & $-1 \cdot 02$ & $0 \cdot 91$ & & $0 \cdot 01$ & $0 \cdot 02$ \\
\hline Block 4-Maternal mental health & & & & & $0 \cdot 10 * *$ & & \\
\hline Symptomatology & $-3 \cdot 84$ & $1 \cdot 39 * * *$ & $-3 \cdot 19$ & $1 \cdot 37 * *$ & & -0.04 & $0.07 * *$ \\
\hline Functioning (self-rated) & $-4 \cdot 41$ & $-2 \cdot 40 *$ & $-4 \cdot 72$ & $-2 \cdot 32 * *$ & & $-0 \cdot 02$ & 0.05 \\
\hline Block 5-Interaction & & & & & $0.07 *$ & & \\
\hline Functioning $\times$ symptoms & $4 \cdot 62$ & $1 \cdot 98 * *$ & $4 \cdot 62$ & $1 \cdot 98 * *$ & & 0.04 & $0.07 * *$ \\
\hline Overall $F_{(11,57)}=2 \cdot 45^{* *}$ & & & Total $R^{2}=$ & & $0 \cdot 32 * *$ & & \\
\hline
\end{tabular}

Note: Unique effects are the change in $R^{2}$ attributable to each predictor with the effects of all other predictors controlled. Shared effects reflect the difference between the zero-order $r^{2}$ for the predictor and the unique effect of that predictor. Negative shared effects reflect reciprocal suppression between symptomatology and functioning. $* p<0 \cdot 10, * * p<0.05, * * *<<0 \cdot 01$. 
Table 5. Hierarchical regression predicting child school efficacy

\begin{tabular}{|c|c|c|c|c|c|c|c|}
\hline \multirow[b]{3}{*}{ Blocks of predictors } & \multicolumn{7}{|l|}{ Coefficients } \\
\hline & \multicolumn{2}{|c|}{ Entry block } & \multicolumn{2}{|c|}{ Final block } & \multirow[b]{2}{*}{ Block $\Delta R^{2}$} & \multicolumn{2}{|c|}{ Effects } \\
\hline & Unstand. B & S.E. & Unstand. B & S.E. & & Shared & Unique \\
\hline $\begin{array}{l}\text { Block } 1 \text { - Child demographics } \\
\text { Sex }(1=\text { male; } 0=\text { female) } \\
\text { Race }(1=\text { white; } 0=\text { non-white }) \\
\text { Age (in years) }\end{array}$ & $\begin{array}{r}-0.03 \\
-0.43 \\
0.01\end{array}$ & $\begin{array}{l}0 \cdot 18 \\
0 \cdot 18^{* *} \\
0 \cdot 06\end{array}$ & $\begin{array}{r}-0.13 \\
-0.40 \\
0.00\end{array}$ & $\begin{array}{l}0 \cdot 18 \\
0 \cdot 18^{* *} \\
0 \cdot 16\end{array}$ & 0.09 & $\begin{array}{l}0.00 \\
0.02 \\
0.00\end{array}$ & $\begin{array}{l}0.01 \\
0.07^{* *} \\
0.00\end{array}$ \\
\hline $\begin{array}{l}\text { Block } 2 \text { - Family stress } \\
\text { Income (\% poverty) } \\
\text { Daily hassles } \\
\text { Available support for parenting }\end{array}$ & $\begin{array}{r}0.13 \\
-0.02 \\
-0.29\end{array}$ & $\begin{array}{l}0 \cdot 17 \\
0 \cdot 03 \\
0 \cdot 19\end{array}$ & $\begin{array}{r}0.05 \\
0.00 \\
-0.30\end{array}$ & $\begin{array}{l}0.17 \\
0.03 \\
0.19\end{array}$ & 0.05 & $\begin{array}{l}0.00 \\
0.02 \\
0.01\end{array}$ & $\begin{array}{l}0.00 \\
0.00 \\
0.03\end{array}$ \\
\hline $\begin{array}{l}\text { Block } 3 \text {-Maternal parenting style } \\
\text { Permissive } \\
\text { Positive directive }\end{array}$ & $\begin{array}{l}-0 \cdot 10 \\
-0 \cdot 11\end{array}$ & $\begin{array}{l}0 \cdot 14 \\
0 \cdot 10\end{array}$ & $\begin{array}{r}-0.04 \\
0.11\end{array}$ & $\begin{array}{l}0 \cdot 15 \\
0 \cdot 10\end{array}$ & 0.03 & $\begin{array}{l}0.01 \\
0.02\end{array}$ & $\begin{array}{l}0.00 \\
0.02\end{array}$ \\
\hline $\begin{array}{l}\text { Block } 4 \text { - Maternal mental health } \\
\text { Symptomatology } \\
\text { Functioning (self-rated) }\end{array}$ & $\begin{array}{r}-0.20 \\
0.35\end{array}$ & $\begin{array}{l}0 \cdot 15 \\
0 \cdot 26\end{array}$ & $\begin{array}{l}0 \cdot 13 \\
0 \cdot 39\end{array}$ & $\begin{array}{l}0.15 \\
0.25\end{array}$ & 0.03 & $\begin{array}{l}-0.01 \\
-0.02\end{array}$ & $\begin{array}{l}0.01 \\
0.03\end{array}$ \\
\hline $\begin{array}{l}\text { Block } 5 \text {-Interaction } \\
\text { Functioning } \times \text { symptoms }\end{array}$ & -0.54 & $0 \cdot 22 * *$ & -0.54 & $0.22 * *$ & $0.08 * *$ & 0.00 & $0.08 * *$ \\
\hline Overall $\mathrm{F}_{(11,57)}=1 \cdot 93^{*}$ & & & Total $R^{2}=$ & & $0.27 * *$ & & \\
\hline
\end{tabular}

Note: Unique effects are the change in $R^{2}$ attributable to each predictor with the effects of all other predictors controlled. Shared effects reflect the difference between the zero-order $r^{2}$ for the predictor and the unique effect of that predictor. Negative shared effects reflect reciprocal suppression between symptomatology and functioning. $* p<0 \cdot 10, * * p<0.05, * * * p<0 \cdot 01$ 
youth report of symptoms was associated with lower maternal report of symptoms $(B=$ $-4 \cdot 38, p<0.01$; unique effect $=0.08, p<0 \cdot 01$ ). Additionally, the interaction between maternal symptoms and community functioning (entered at block 5) modified the main effect of maternal symptoms on youth symptoms and significantly added to variance explained, $\left(\Delta \mathrm{F}(1,57)=5 \cdot 89, p=0 \cdot 02 ; \Delta R^{2}=0 \cdot 06\right)$. Examination of the plot of this effect showed that youth depressive symptoms were higher when mothers had a combination of low functioning and few symptoms. The simple slope of the regression of depression on maternal symptoms was negative and significant at 1 S.D. below mean functioning $(B=-5 \cdot 30$, $p<0.001)$; at 1 S.D. above mean functioning, the simple slope of depression on symptoms was also negative but not significantly different from zero $(B=-1 \cdot 12, p=0 \cdot 51)$. The full set of predictors explained $38 \%$ of variance in youth depression.

\section{Anxiety}

Results for the prediction of youth anxiety, presented in Table 4, were similar to those for youth depression. That is, neither child demographic nor family stress variables had significant relationships with youth anxiety, although there was a trend toward higher anxiety levels for girls $(B=-2 \cdot 97, p=0.09)$. In block 3 , parenting style had a trend-level relationship with anxiety $\left(\Delta F(2,60)=2.64, p=0.08 ; \Delta R^{2}=0.07\right)$; specifically, more permissive maternal parenting was associated with higher levels of youth anxiety $(B=2 \cdot 60$, $p=0.06)$. With all other variables in the model controlled, neither child sex nor permissive parenting showed a unique effect on the youth's anxiety.

Effects of maternal mental health. We did find a significant added effect for maternal mental health, in that it added significantly to the prediction of youth anxiety, $\Delta F(2,58)=3 \cdot 86, p=0.03$; as with depressive symptoms, youths reported more symptoms of anxiety in families where mothers reported fewer psychiatric symptoms $(B=-3 \cdot 84$, $p<0.01$; unique effect $=0.07, p<0.05)$. At trend level, youth also reported more symptoms of anxiety when mothers reported lower community functioning $(B=-4 \cdot 41, p=0 \cdot 07$; unique effect $=0.05, p<0.05)$. The marginally significant effect of functioning, which was not seen in the matrix of zero-order correlations, was the result of controlling for symptomatology in the regression analysis; with symptomatology omitted, maternal functioning had no significant direct effect on youth anxiety. However, the interaction between maternal symptoms and community functioning (entered at block 5) modified the main effect of maternal symptoms on youth anxiety and significantly added to variance explained $\left(\Delta F(1,57)=5 \cdot 43, p=0 \cdot 02 ; \Delta R^{2}=0 \cdot 07\right)$. Examination of the plot of this effect showed a similar surprising result as found with youth depression-youth anxiety was higher when mothers had a combination of low functioning and low symptoms. The simple slope of anxiety on maternal symptoms was negative and significant at 1 S.D. below mean functioning $(B=-5 \cdot 23, p<0 \cdot 001)$; at 1 S.D. above mean functioning, the simple slope was also negative but not significantly different from zero $(B=-0 \cdot 77, p=0 \cdot 68)$. The full set of predictors explained $32 \%$ of the variance in youth anxiety.

\section{School efficacy}

The youth-perceived school efficacy had fewer significant relationships with the set of independent variables, as can be seen in Table 5. As with depression and anxiety, neither the block of child demographics nor the block of family stress variables made a significant contribution to the prediction of school efficacy, although race had a significant individual 
relationship $(B=-0.43, p=0.02$; unique effect $=0.07, p<0.05)$, indicating that white youth reported lower levels of school efficacy. In contrast to the prediction of depression and anxiety, school efficacy was not significantly related to parenting style (block 3).

Effects of maternal mental health For school efficacy, we did not find a significant main effect of maternal mental health (block 4), However, as with youth depressive symptoms and anxiety, we did find an interaction between maternal symptoms and community functioning (entered at block 5 ), which significantly added to variance explained $\left.\Delta F(1,57)=6 \cdot 25, p=0 \cdot 02 ; \Delta R^{2}=0 \cdot 08\right)$. Examination of the plot of this effect showed that youth efficacy was lower when mothers had a combination of low functioning and low symptoms. At 1 S.D. below mean functioning, the simple slope of school efficacy on maternal symptoms was positive and significant $(B=0.39, p<0.03)$, but at 1 S.D. below mean functioning, the simple slope was negative and non-significant $(B=-0 \cdot 15, p=0 \cdot 47)$. Overall, the explanatory variables accounted for $27 \%$ of the variance in school efficacy.

\section{Exploration of robustness of results}

Although the significant effects of the interaction between maternal symptoms and community functioning were consistent across the three youth outcomes, their contribution was unexpected and their direction surprising. To verify that these findings were not the result of extreme outliers or other anomalies, the effects were examined both graphically and statistically. Scatterplots of maternal symptoms and functioning showed no noticeable outliers. As expected, a relatively small group of 10 cases fell below the median on both symptoms and functioning. These cases showed a range of scores on the three youth outcome variables, with only two cases falling beyond the interquartile range on more than one of the three outcomes. Trimming the two highest and two lowest scores from this group of ten cases and rerunning the analyses produced no difference in the regression results. For all three youth outcomes, the interaction of maternal symptoms and functioning remained significant and the magnitude of the effect did not decline, providing some support for the robustness of the findings.

\section{Discussion}

Our goal was to examine effects of parenting style in the context of family stresses, and to explore the extent that maternal mental health added to variance explained once her parenting style and family stresses were taken into account, using a sample of mothers with serious mental illness. Our research fits with an emerging literature connecting parenting style with child depressive symptoms. However, unlike other research that typically asks if parenting style has any effect once maternal mental health has been taken into account, we asked whether mental health issues continue to predict child psychological functioning once family context and parenting issues have been taken into account.

We hypothesized that family context, parenting style, and maternal mental illness would each influence the teen's psychological well-being, after controlling for the effects of youth sex, race, and age. We found no effects of age, modelled either as continuous or as a series of dummy-coded categorical variables; this is likely due to the restriction of range on age in this sample, with $77 \%$ under age 15 . We also found only one marginal effect of sex: girls had marginally higher scores on anxiety. We did not find the more commonly observed effect of higher depression scores for girls. Because this effect typically becomes more pronounced with age and the bulk of the literature focuses on white middle-class youth, the absence of a 
gender effect is also likely due to the restricted age range of the sample as well as the inclusion of low-income and racially diverse youth. The positive effect of African American race on school efficacy parallels the consistent finding of higher (or equal) self-esteem among African American than white youths (e.g. Porter and Washington, 1979; Crocker and Major, 1989).

In our sample of adolescent children and their mothers, we did not find an effect of the family contextual factors we assessed, including income, maternal support for parenting and maternal hassles. It is possible that our relatively low-income sample of mothers were not sufficiently heterogeneous, or that our measures were not sufficiently sensitive, so that this null finding cannot be taken to mean that poverty, daily hassles, and parenting support do not relate to adolescent well-being among mothers with a serious mental illness.

In spite of the possible limitations in our sample, we found some evidence of the hypothesized effect of parenting style on youth mental health. Congruent with literature suggesting that structure is helpful for teens (e.g. Darling and Steinberg, 1993); we found that permissive parenting related to higher symptoms of depression and anxiety and that a positive, directive style related to fewer symptoms of depression. That anxiety, lack of positive self-confidence/efficacy and depression have somewhat independent antecedents is reasonable given the literature on depression in adolescence suggesting that while anxiety is a common concomitant of depression, the two do not always co-occur (Allen-Meares et al., in press). Parenting style did not predict school efficacy, perhaps because school efficacy in adolescence is not only a function of family influences but also other factors, such as positive school bonding, positive relationships with teachers, and social competence (Resnick et al., 1998).

Moreover, even though we found a relationship between parenting and youth mental health, the nature of the causal path may not be unidirectional. Although we assessed mothers' parenting on an average 2 years prior to assessing youth symptoms of anxiety and depression, it is possible that prior child characteristics influenced maternal parenting style. Mothers may have become more permissive and less directive in response to problematic characteristics in their children - when children are anxious and depressed, mothers may become uncertain as to how to parent. Even though our youth data were collected after our maternal data, it is not possible to rule out this possibility without additional longitudinal data that would allow us to control for the effects of previous youth symptoms on later parenting behaviours.

In addition to the effects of parenting style, in our current data, we found evidence of the influence of maternal mental illness on youth mental health even after family context and parenting style were taken into account. Surprisingly, low maternal expression of psychiatric symptoms related to increased risk of youth depressive and anxiety-related symptoms. This effect was moderated by the significant interaction between symptoms and functioning; teens reported more depressive symptoms and more anxiety, and they felt less efficacious when their mothers were low functioning and also not evidencing many overt symptoms. This is surprising since a priori it would seem equally likely that youth well-being would be especially impaired when mothers were low functioning and highly symptomatic.

In attempting to understand these results, we speculate that when mothers were not functioning well, but the youth could not easily attribute these problems to mental illness because their mothers did not overtly evidence symptoms, youths might feel more stressed by mother's lack of normal daily activities and perhaps blame themselves more, feeling more depressed, anxious, and less efficacious as a result. It is possible that for some mothers, 
medications control overt symptoms but do not improve functioning. Another possibility is that these mothers were over medicated-controlling their symptoms but having a deleterious effect on functioning. Unless the teenaged children know about their mother's mental illness and understand the effects of the medications, their mother's lack of everyday functioning will be perplexing - making their home lives different from their peers, perhaps increasing the sense of self-blame. In our current research, we are exploring what mothers tell their children about their mental illness to begin to explore this possibility. Finally, it is possible that mothers with few evidenced symptoms but low community functioning depend on their children for help because the lack of overt symptoms reduces the likelihood of obtaining services from community mental health or other agencies.

It is also possible that the association between low symptoms, low functioning and low child well-being could be spurious - due to a third, non-assessed variable. For example, both low maternal symptom reports and elevated youth risk could be the result of unacknowledged or untreated maternal mental health difficulties. In exploring the possibility of alternative explanations in this sample, we assessed whether maternal report of substance abuse or intensity of service receipt might clarify the finding. Neither past substance abuse nor substance abuse at the time of the maternal interview mediated the relationship between low symptoms, low functioning, and low youth well-being. We did find that women who reported lower levels of symptoms tended also to report receiving less intensive mental health services $(r=0 \cdot 38)$. However, the report of mental health service receipt was not correlated with the interaction between symptoms and functioning and was not correlated with youth well-being as measured by symptoms of depression, anxiety, and efficacy. So this cannot be a full explanation of this finding.

The results of this study should be seen as tentative, in light of the small sample and the relatively complex model. Especially tentative are the unexpected direction of the effect of maternal symptoms on youth depression and anxiety and the complex interaction between maternal functioning and symptomatology. Because they were not initially hypothesized, these results are particularly susceptible to the effects of sampling error and model overfitting. Although intriguing, these results require validation in another, preferably larger sample. Prospective, longitudinal research also would be helpful in sorting out causal order and delineating mediational paths.

In our on-going longitudinal study of mothers and their teenaged children, we are beginning to explore further possible interpretations - examining both maternal and agency records of service receipt over time, and also beginning to gather some initial data about what mothers tell their teenaged children about their mental illness. Data from the current study provide evidence that parenting style matters for children of mothers with a serious mental illness, suggest that maternal symptoms and functioning need to be taken into account and highlight the complexity of understanding how a mother's mental illness may influence the well-being of her adolescent children. Mental illness remains a stigmatizing condition, which means that mothers may not share information about their mental illness, or even tell their teenaged children that they have a mental illness, either because they are unsure how to share this with their children or potentially because they have not been provided the tools to do so by their care provider. Mothers may have only vague information about their mental health problem and can be unsure what to tell their children, not wanting to frighten them. Indeed in the current study, mothers were guaranteed confidentiality with regard to their mental illness and we do not know whether their teenaged children knew of the mental illness since we could not ask any direct questions that might break a mother's 
confidentiality. Future research on what parents are told and what they tell their children is much needed. Much like conversations about the birds and the bees, parents may assume that children know but be unwilling to discuss specifics.

\section{Acknowledgements}

Funding for this project came from NIMH grant \#1 R01 MH57495 01, the Office of the Vice President for Research and the CHGD-Poverty Research Fund, University of Michigan. The support of the Center for Advanced Studies in the Behavioral Sciences, Stanford during preparation of this manuscript is gratefully acknowledged.

\section{References}

Aiken, L. S. and West, S. G. (1991). Multiple regression: Testing and interpreting interactions. Newbury Park, CA: Sage.

Allen-Meares, P., Colarossi, L., Oyserman, D. and Yosikazu DeRoos, Y. (in press). Assessing depression in childhood and adolescence: a guide for social work practice. Child and Adolescent Social Work Journal.

Arbelle, S., Magharious, W., Auerbach, J. G., Hans, S. L., Marcus, J., Baruch S. and Caplan, R. (1997). Formal thought disorder in offspring of schizophrenic parents. Israel Journal of Psychiatry and Related Sciences, 34(3), 210-221.

Bandura, A., Barbaranelli, C., Caprara, G.V. and Pastorelli, C. (1996). Multifaceted impact of selfefficacy beliefs on academic functioning. Child Development, 67(3), 1206-1222.

Barrera, M. (1988). Notes on deriving network indices from the ASSIS. Tempe: Department of Psychology, Arizona State University.

Baumrind, D. (1978). Manual for the rating scales for parents of adolescent children. Unpublished manual, Institute of Human Development, University of California at Berkeley.

Beardslee, W. R., Keller, M. B., Lavori, P. W., Staley, J. and Sacks, N. (1993). The impact of parental affective-disorder on depression in offspring: a longitudinal follow-up in a nonreferred sample. Journal of the American Academy of Child and Adolescent Psychiatry, 32(4), 723-730.

Beardslee, W. R., Versage, E. M. and Gladstone, T. R. G. (1998). Children of affectively ill parents: a review of the past 10 years. Journal of the American Academy of Child and Adolescent Psychiatry, $37(11), 1134-1141$.

Boyle, M. H. and Pickles, A. (1997). Maternal depressive symptoms and ratings of emotional disorder symptoms in children and adolescents. Journal of Child Psychology and Psychiatry and Allied Disciplines, 38(8), 981-992.

Bybee, D., Mowbray, C. T., Oyserman, D. and Lewandowski, L. (2001). Variability in community functioning of mothers with serious mental illness. Unpublished manuscript. Ann Arbor, MI: University of Michigan.

Chang, K. K. D., Steiner, H. and Ketter, T. A. (2000). Psychiatric phenomenology of child and adolescent bipolar offspring. Journal of the American Academy of Child and Adolescent Psychiatry, 39(4), 453-460.

Cole, D. A., Hoffman, K., Tram, J. M. and Maxwell, S. E. (2000). Structural differences in parent and child reports of children's symptoms of depression and anxiety. Psychological Assessment, 12(2), $174-185$.

Conger, R. D., Patterson, G. R. and Ge X. J. (1995). It takes two to replicate: a mediational model for the impact of parents' stress on adolescent adjustment. Child Development, 66(1), 80-97.

Crocker, J. and Major, B. (1989). Social stigma and self-esteem: the self-protective properties of stigma. Psychological Review, 96, 608-630.

Darling, N. and Steinberg, L. (1993). Parenting style as context: an integrative model. Psychological Bulletin, 113, 487-496. 
Davies, P. and Windle, M. (1997). Gender-specific pathways between maternal depressive symptoms, family discord, and adolescent adjustment. Developmental Psychology, 33(4), 657-668.

Downey, G. and Coyne, J. C. (1990). Children of depressed parents - an integrative review. Psychological Bulletin, 108(1), 50-76.

Duffy, A., Alda, M., Kutchee, S., Fusee, C. and Grof, P. (1998). Psychiatric symptoms and syndromes among adolescent children of parents with lithium-responsive or lithium-nonresponsive bipolar disorder. American Journal of Psychiatry, 155(3), 431-433.

Fendrich, M., Warner, V. and Weissman, M. M. (1990). Family risk-factors, parental depression, and psychopathology in offspring. Developmental Psychology, 26(1), 40-50.

Fergusson, D. M., Horwood, L. J. and Lynskey, M. T. (1995). Maternal depressive symptoms and depressive symptoms in adolescents. Journal of Child Psychology and Psychiatry and Allied Disciplines, 36(7), 1161-1178.

Ganzach, Y. (1997). Misleading interaction and curvilinear terms. Psychological Methods, 2(3), 235-247.

Grigoroiu-Serbanescu, M., Christodorescu, D., Totoescu, A. and Jipescu, I. (1991). Depressive disorders and depressive personality traits in offspring aged 10-17 of bipolar and of normal parents. Journal of Youth and Adolescence, 20(2), 135-148.

Hammen, C., Adrian, C., Gordon, D., Burge, D., Jaenicke, C. and Hiroto, D. (1987a). Children of depressed mothers - maternal strain and symptom predictors of dysfunction. Journal of Abnormal Psychology, 96(3), 190-198.

Hammen, C., Gordon, D., Burge, D., Adrian, C., Jaenicke, C. and Hiroto, D. (1987b). Maternal affective-disorders, illness, and stress - risk for childrens psychopathology. American Journal of Psychiatry, 144(6), 736-741.

Kovacs, M. (1992). Children's depression inventory manual. North Tonawanda, NY: Multi-Health Systems.

Lapalme, M., Hodgins, S. and Laroche, C. (1997). Children of parents with bipolar disorder: a metaanalysis of risk for mental disorders. Canadian Journal of Psychiatry-Revue Canadienne De Psychiatrie, 42(6), 623-631.

Lazarus, R. S. and Folkman, S. (1984). Stress, appraisal, and coping New York, NY: Springer Publishing Company, pp. 286-333.

Mowbray, C., Schwartz, S., Bybee, D., Spang, J., Rueda-Riedle, A. and Oyserman, D. (2000). Mothers with a mental illness: stressors and resources for parenting and living. Families in Society - the Journal of Contemporary Human Services, 81(2), 118-129.

Oyserman, D., Mowbray, C. T., Meares, P. A. and Firminger, K. B. (2000). Parenting among mothers with a serious mental illness. American Journal of Orthopsychiatry, 70(3), 296-315.

Porter, J. and Washington, R. (1979). Black identity and self-esteem: a review of studies of Black selfconcept. Annual Review of Sociology, 5, 53-74.

Resnick, M., Bearman, P., Blum, R., Bauman, K., Harris, K., Jones, J., Tabor, J., Beuhring, T., Sieving, R., Shew, M., Ireland, M., Bearinger, L. and Udry, J. (1998). Protecting adolescents from harm: findings from the National Longitudinal Study of Adolescent Health. In Adolescent Behavior and Society: A Book of Readings, 5th Edn, Muuss, R. E. and Porton, H.D. (Eds). New York: McGraw Hill, pp. 376-395.

Reynolds, C. and. Richmond, B. (1978). What I think and feel: a revised measure of children's manifest anxiety. Journal of Abnormal Child Psychology, 6(2), 271-280.

Shern, D. L., Wilson, N. Z., Coen, A. S., Patrick, D. C., Foster, M. and Bartsch, D. A. (1994). Client outcomes: 2 longitudinal client data from the Colorado treatment outcome study. Milbank Quarterly, 72(1), 123-148.

Stollak, G. E., Scholom, A., Kallman, J. R. and Saturansky, C. (1973). Insensitivity to children: responses of undergraduates to children in problem situations. Journal of Abnormal Child Psychology $1(2), 169-180$.

Tannenbaum, L. and Forehand, R. (1994). Maternal depressive mood-the role of the father in preventing adolescent problem behaviors. Behaviour Research and Therapy, 32(3), 321-325.

U. S. Census Bureau (1996). Poverty thresholds in 1996, by size of family and number of related children under 18 years. U.S. Census Bureau, Current Population Survey. Bureau of the Census, Washington, DC. 